\title{
FAKTOR - FAKTOR YANG MEMPENGARUHI PENDAPATAN DRIVER GOJEK
}

\author{
Eva Marsusanti ${ }^{1}$, Susilawati ${ }^{2}$, Rusli Nugraha ${ }^{3}$ \\ Tya Septiani Nurfauzia Koeswara ${ }^{4}$ \\ 1,2,3AMIK BSI SUKABUMI \\ e-mail:eva.emr@bsi.ac.id, susi.ssl@bsi.ac.id, rusli.rng@bsi.ac.id,tya.tsf@bsi.ac.id
}

\begin{abstract}
Abstrak
Driver Gojek online di Sukabumi semakin meningkat, mereka saling bersaing untuk medapatkan penumpang. Hal ini berpengaruh terhadap pendapatan mereka,tidak hanya disebabkan oleh pesaing baru seperti Grab,tetapi ada juga beberapa faktor yang mempengaruihi pendapatan driver Go-jek,seperti:,kenaikan BBM dan perubahan sistem point. Penelitian ini dilakukan di kota Sukabumi dengan jumlah sampel sebanyak 100 responden, Metode yang digunakan dalam penelitian ini adalah probability sampling khususnya simple random sampling. Pengumpulan data dilakukan dengan metode wawancara, dan observasi. Berdasarkan hasil wawancara dan observasi, ditemukan bahwa bahwa pesaing transportasi online lainnya (Grab), kenaikan BBM dan perubahan slstem poin berpengaruh terhadap pendapatan driver GO-JEK. Namun dari hasil wawancara, pesaing dan sistem point memiliki pengaruh $75 \%$ dan sedangkan kenaikan BBM hanya berpengaruh terhadap pendapatan driver Go-jek sebesar 25\% saja.

Kata Kunci : Gojek,Pesaing Baru,Kenaikan Bbm,Sistem Point,Pendapatan Pengemudi Gojek
\end{abstract}

Abstract
Gojek online drivers in Sukabumi are increasing, they are competing to get passengers. This affects their income, not only caused by new competitors such as Grab, but there are also several factors that influence the Go-jek driver's income, such as: the increase in fuel prices and changes in the system point. This research was conducted in the city of Sukabumi with a total sample of 100 respondents. The method used in this study is probability sampling, especially simple random sampling. Data collection was done by interview and observation. Based on the results of interviews and observations, it was found that other competitors of online transportation (Grab), increases in fuel prices and changes in system points affected the revenue of GO-JEK drivers. But from the results of interviews, competitors and point systems have an influence of $75 \%$ and while the increase in fuel only affects the Go-jek driver's income by only $25 \%$.

Keyword: Gojek,Competitor, Point System,BBM Increase, Gojek Driver Income

\section{Pendahuluan}

mobilitas masyarakat, tentunya membutuhkan sarana transportasi yang dapat memberikan pergerakan dan perpindahan dari satu tempat ke tempat yang lain dengan cepat, walaupun jarak tempuhnya jauh. Dewasa ini terdapat terobosan terbaru, yakni inovasi transportasi berbasis aplikasi online yang didukung oleh teknologi komunikasi melalui smartphone. Transportasi berbasis aplikasi online ini merupakan penggabungan dari segi jasa transportasi ojek dan teknologi komunikasi. Dari sekian banyaknya transportasi berbasis aplikasi online yang terdapat di Indonesia, Go-Jek adalah yang paling banyak digunakan oleh masyarakat. Hal tersebut berdasarkan lembaga riset global Growth for Knowledge (Gfk) membuktikan bahwa pengguna aplikasi online Go-Jek mencapai 21,6\%5. Go-Jek adalah sebuah perusahaan teknologi berjiwa sosial yang bertujuanuntuk meningkatkan kesejahteraan pekerja diberbagai sektor informal di Indonesia. Selain jasa dan teknologi komunikasi, transportasi berbasis aplikasi online juga dilengkapi dengan fitur Global Positioning System atau yang lebih dikenal dengan GPS untuk memberikan informasi keberadaan pengemudi dan pengguna dengan rute terdekat.

Seiring berkembangnya zaman dan teknologi, transportasi juga mengalami perkembangan yang pesat, seperti : Gojek, 
Grab, taxi online dan Uber. Jenis transformasi inilah yang dinamakan transportasi online. Transportasi online ini sangat mempermudah dan mempercepat kerja, kita,hanya tinggal download aplikasinya digedget kita dan klik sana klik sini maka pengemudi langsung datang menjemput.transportasi ini sangat menguntungkan kedua belah pihak. Pengemudi sangat senang karna hanya standby diposisinya sambil menunggu pesenan dari penumpang masuk,tak seperti transportasi biasa,dimana pengemudi harus teriak dan ngetem dulu nyari penumpang.Begitu juga sebaliknya, penumpang juga diuntungkan karna tak harus menunggu lama dan berdesakan didalam transportasi seperti: bus,mikrolet dan angkot, serta tukang ojek tak harus nunggu giliran untuk narik penumpang. Jauh berbeda dengan go-jek yang semuanya udah diatur oleh operator.apalagi penumpang dimanjakan dengan pilihan pembayaran secara tunai dan go-pay lebih murah lagi dari pembayaran tunai.ditambah lagi bonus - bonus yang diberikan kepada penumpang jika sering mengisi saldo go-pay nya.

Alasan lain penumpang lebih memilih Gojek karena faktor kenyamanan dan kecepatan. (Tamin et. al, 1999 dalam Amajida (2016)). Dagun et. al (2006) dalam Rifusua (2010) menyatakan bahwa, transportasi publik yang baik harus memenuhi tiga kriteria dasar, yaitu: kenyamanan,keamanan dan kecepatan. Hampir semua kriteria ini dimiliki oleh transportasi online yang bernama Gojek.

Namun akhir- akhir ini driver Go-jek mulai mengeluh karna pendapatan mereka mulai berkurang. Banyak driver bilang Gojek hanya manis di awal tahun kemunculannya saja, akan tetapi semakin hari semakin menurun penghasilan para drivernya, sehingga banyak sekali keluh kesah driver di medsos bahkan tak jarang bersitegang pun masih terjadi antar opang dan ojek online di berbagai daerah.

Tidak seperti awal kemunculanya, dimana pengemudi bisa membeli motor dan mobil baru dan menyicilnya dari hasil men Go-jek online. Ada beberapa faktor yang mempengaruhi pendapatan driver online, mulai dari munculnya pesaing baru,kenaikan Bahan Bakar Minyak (BBM) dan berubahnya sistem poin.

Penelitian mengenai faktor-faktor yang mempengaruhi pendapatan driver Gojek juga pernah dilakukan oleh Deddi Cahyadi (2016) yang menyatakan bahwa berdasarkan hasil analisis regresi berganda menggunakan program eview 9, menunjukkan bahwa usia,jam kerja, jumlah penumpang berdampak positif,sedangkan tingkat Pendidikan berpengaruh negative terhadap pendapatan driver Gojek.

Berdasarkan penelitian tersebut, peneliti juga ingin mengetahui faktot-faktor apalagi yang dapat mempengaruhi pendapatan pengemudi Go-jek online yang ada di kota Sukabumi.

\section{Metode Penelitian}

Tahap awal dalam memfokuskan penelitian ini adalah dengan melaksanakan pengamatan yang bersifat grand tour observation. Istilah grand tour observation mengacu pada pengalaman yang diperoleh oleh peneliti dalam pelaksanaan pada tahap awal. Menurut Sugiyono (2013:208), menjelaskan bahwa untuk mempertajam penelitian kualitatif, peneliti harus menetapkan focus penelitian yang merupakan domain tunggal atau beberapa domain terkait dengan situasi sosial. Fokus yang sebenarnya dalam penelitian kualitatif diperoleh setelah peneliti melakukan grand tour observation dan gran tour question atau yang disebut dengan istilah penjelajahan umum.

Penelitian ini menggunakan tipe penelitian deskriptif dengan pendekatan kualitatif. Dalam penelitian yang menggunakan tipe penelitian deskriptif bertujuan untuk mendapatkan gambaran umum tentang faktor-faktor apa saja yang mempengaruhi pendapatan driver Go-jek

Metode yang digunakan dalam penelitian ini adalah probability sampling khususnya simple random sampling. Margono (2004:126) menyatakan bahwa simple random sampling adalah teknik untuk mendapatkan sampel yang langsung dilakukan pada unit sampling. Cara demikian dilakukan bila anggota populasi dianggap homogen. Teknik ini dapat dipergunakan bilamana jumlah unit sampling di dalam suatu populasi tidak terlalu besar.

Pengumpulan data dilakukan dengan metode observasi dan wawancara, Nasution dalam Sugiyono (2010: 226) menyatakan bahwa observasi adalah dasar dari semua ilmu pengetahuan, para ilmuan hanya dapat bekerja berdasarkan data, yaitu fakta mengenai dunia kenyataan yang diperoleh melalui observasi. Berdasarkan definisi 
diatas, maka observasi merupakan pengamatan langsung ke lokasi penelitian untuk mendapatkan data atau gambaran yang jelas dari objek penelitian yang berhubungan dengan masalah yang akan diteliti.

Sementara menurut Esterberg dalam Sugiyono (2010:231) wawancara adalah pertemuan dua orang untuk bertukar informasi dan ide melalui tanya jawab, sehingga dapat dikontruksikan makna dalam suatu topik tertentu

Populasinya adalah semua driver Gojek yang ada di Kota Sukabumi.Sedangkan jumlah sampelnya sebanyak 100 responden. Untuk mendapatkan jawaban yang mendalam, akurat, dan dapat dipertanggung jawabkan, peneliti melakukan pengumpulan data dengan menggunakan wawancara mendalam. Wawancara mendalam (indepth interview) adalah teknik pengumpulan data dengan cara melakukan percakapan secara intensif dengan informan penelitian. Wawancara ini dilakukan secara terbuka dengan menggunakan pedoman wawancara yang telah dibuat sebelumnya. Hasil dari wawancara mendalam tersebut akan menjadi data primer dalam penelitian ini.

Setelah semua data terkumpul, akan dilakukan analisis data dengan mengelompokkan data dari hasil wawancara mendalam. Pengelompokan disesuaikan dengan item pertanyaan yang telah dibuat untuk menjawab rumusan masalah dalam penelitian ini. Menurut Creswell dalam Research Design: Pendekatan Kualitatif, Kuantitatif dan Mixed (2010:276 - 284) terdapat langkah - langkah dalam analisis data, antara lain :

a. Mengolah dan mempersiapkan data untuk dianalisis.

b. Membaca keseluruhan data.

c. Menganalisis lebih detail dengan mengkoding data.

d. Menerapkan proses koding untuk mendeskripsikan setting, subyek, kategori dantema yang akan dianalisis.

e. Menyajikan kembali deskripsi dan tema dalam narasi atau laporan secara kualitatif dengan menerapkan pendekatan naratif dalam menyampaikan hasil analisis yang meliputi kronologi peristiwa, tema tertentu, atau keterhubungan antar tema.

f. Interpretasi atau pemaknaan data

\section{Hasil Dan Pembahasan}

Perusahaan ojek online bernama PT Go-Jek Indonesia ini sudah didirikan sejak 2010 di Jakarta. Saat ini, CEO dijabat oleh Nadiem Makarim, pemuda Indonesia jebolan Harvard Business School, Universitas Harvard, Amerika Serikat. Ide dari mendirikan Gojek ini dari pengalaman pribadi Nadiem menggunakan transportasi ojek hampir setiap hari ke tempat kerjanya untuk menembus kemacetan di Jakarta.Sebagai seorang yang sering menggunakan transportasi ojek, Nadiem melihat sebagian besar pengemudi ojek hanya mangkal menunggu penumpang.

Padahal mereka bisa mendapatkan penghasilan yang lumayan jika banyak penumpang. Selain itu, la melihat ketersediaan jenis transportasi ini tidak sebanyak transportasi lainnya sehingga serinkali cukup sulit untuk dicari. I menginginkan ojek yang bisa ada setiap saat dibutuhkan. Dari pengalaman tersebut, Nadiem melihat adanya peluang untuk membuat sebuah layanan yang dapat menghubungkan penumpang dengan pengemudi ojek.

Maka pada tanggal 13 Oktober 2010, Go-jek resmi berdiri dengan 20 pengemudi ,dimana saat itu masih mengandalkan call center untuk menghubungkan penumpang dengan pengemudi. Akhirnya, pada tanggal 7 januari 2015 Go-jek meluncurkan aplikasi berbasis Android dan IOS untuk menggantikan sistem pemesanan manggunakan call center. Saat ini,Go-jek telah tersedia di 50 kota di seluruh Indonesia.

Hasil karya anak Indonesia ini telah berkembang pesat bahkan sekarang para pengemudi ojek yang dulunya menentang adanya aplikasi ini, sekarang beralih dan bergabung menjadi driver Gojek online.Seiring berkembangnya bisnis transportasi online serta menjamurnya penggunaan layanan Go-jek di Jabodetabek membuat perusahaan layanan transportasi pemesanan taksi asal Malaysia, meluncurkan aplikasi yang serupa Gojek yaitu Grab. Layanan ini diluncurkan pada bulan Mei 2015. Sekarang Grab sudah memasuki kota Sukabumi dan perkembangannya hampir sama dengan Gojek. Hal inilah yang mulai dikeluhkan oleh pengemudi Gojek. Mereka harus siap dan pintar dalam menarik hati penumpang agar tidak berpindah ke pesaingnya yang baru. 
Selain itu sistem poin juga dikeluhkan oleh pengemudi Gojek, dimana sisitem poin saat Gojek pertama kali beroperasi tidak sama dengan sistem poin yang sekarang ini.

Berdasarkan hasil wawancara dengan pengemudi Gojek sebagai responden, mereka merasa pendapatan mereka tidak seperti dulu karena adanya pesaing baru yang bernama Grab.Bahkan ada yang memiliki dua aplikasi sekaligus Gojek juga Grab pun juga, sholahuddin (25 tahun) ,"Saya punya dua aplikasi ,alasannya buat jaga-jaga kalau Gojek sepi ,saya masih bisa dapat tambahan penghasilan dari Grab,"ujarnya.tapi tidak semua driver Gojek berpaling ke pesaing baru atau "mendua",banyak diantara mereka tetap bertahan dengan Gojek. kami harus mencari tambahan dengan memperbanyak poin,tak masalah kalau harus lembur sampai malam (Noval, 22 tahun).

Jika poin belum mencapai target,para pengemudi Gojek menawarkan isi Go-pay ke penumpangnya. Sulitnya mendapat poin maksimal, memaksa mereka memperpanjang jam kerja. Namun, dengan menjajakan top up Gopay tersebut menjadi alternative untuk mempercepat pertambahan poin. Jika mereka berhasil menawarkan ke penumpang untuk top up Gopay, maka mereka akan mendapat poin tambahan.

Bicara masalah poin dan bonus, para driver mengeluh karena bonus yang mereka peroleh dari poin yang sekarang tidak sama dengan sistem bonus diawal munculnya aplikasi ini pada tahun 2015,dimana gojek memberlakukan tarif Bruto sebesar Rp. $4000 \mathrm{~km}$ akan tetapi itu belum di potong komisi untuk PT gojek itu sendiri sebesar $20 \%$ sehingga tarif yang di dapat oleh seorang driver sebesar Rp 3200/km, Semakin banyak nya driver bergabung di berbagai kota gojek pun mulai menurunkan tarifnya puncaknya awal tahun 2017 gojek memberikan tarif netto $\mathrm{Rp} 2000 / \mathrm{km}$ dengan alasan pelanggan gojek semakin banyak dan demi sehat dan kelancaran perusahaan. Tak jarang banyak sekali driver yang mengeluh akan murahnya tarif. bonus di berikan kepada driver apabila telah mencapai

1. Poin 14 bonus sebesar Rp. 20.000

2. Poin 16 bonus sebesar Rp. 30.000

3. Poin 20 bonus sebesar Rp. 40.000

Dengan syarat performa $40 \%$ (order yang di ambil/dijalankan dari order yang masuk). Driver Gojek akan medapatkan bonus jika sudah mencapai target point 14, dan seterusnya. Jadi dalam sehari driver Gojek harus narik sebanyak 12 kali,kalau ingin bonus mereka harus narik lagi 2 penumpang Ig biar mendapat poin 14.

Bonus yang mereka peroleh berdasarkan poin,berikut rincian poin:

Dulu

Komisi tunai jika menjalankan order

$6-10 \mathrm{~km}=\operatorname{Rp} 1.500$

$10-20 \mathrm{~km}=\operatorname{Rp} 3.000$

Lebih dari $20 \mathrm{~km}=\operatorname{Rp} 6.000$

Order jam $23.00-05.00=$ Rp 3.000

Order di area yang telah ditentukan $=\mathrm{Rp}$

3.000

Ini berarti dulu para driver Gojek tidak mendapatkan bonus tunai jika menjalankan order di bawah jarak $6 \mathrm{~km}$.

Sekarang

Poin dasar layanan $=1$ Poin

Komisi tunai jika menjalankan order:

Order jam $23.00-05.00=$ Rp 3.000

Poin maximum yang bisa didapatkan dari order adalah 1, Apalagi sekarang pengemudi driver hanya mendapatkan bonus tunai kalau menjalankan order jam 23.00 - 05.00.Jadi jelas kalau sistem poin dan bonus sangat mempengaruhi pendapatan driver Gojek.

Ada lagi aturan baru untuk para pemgemudi Gojek versi 1.0.101. Bagi pengemudi,kebijakan dan aplikasi baru ini menutup ruang terhadap bonus mereka. Penerimaan order itu harus mencapai 70 persen untuk mendapatkan bonus harian. Berdasarkan aturan baru ini, para pengemudi tidak bisa menolak order penumpang yang diarahkan oleh manajemen Gojek. Para pengemudi hanya memiliki waktu selama 10 detik untuk mengambil order itu. Jika dalam batas maksimal 10 detik panggilan pesanan tidak ditanggapi, maka otomatis ada penilaian minus bagi pengemudi Gojek. Pengemudi bisa saja tidak memperoleh nilai kinerja harian yang ditentukan perusahaan yaitu sebesar 70 persen. Artinya pengemudi hanya mamperoleh uang sewa yang hanya diberikan oleh penumpang. Para pengemudi mengeluhkan sistem ini karena sulit untuk mendapatkan bonus.

Tidak hanya faktor pesaing baru dan sistem poin saja yang dapat mempengaruhi pendapatan mereka, namun 3 bulan terakhir di awal bulan Juli 2018, Pertamina telah menaikkan harga bahan bakar minyak (BBM) non-subsidi, seperti Pertamax, Pertamax Turbo, Pertamina Dex, dan 
Dexlite. Kenaikan ini pun mendapatkan berbagai respon dari masyarakat termasuk driver Gojek (Siti Nur Azzura). Di bidang transportasi, Sekretaris Jenderal (Sekjen) Asosiasi Driver Online (ADO) Sumsel, Malwadi, menerangkan kenaikan itu jelas ada pengaruhnya. Apalagi banyak taksi online (taksol) maupun ojek online (ojol) gunakan BBM non-subsidi seperti pertalite dan pertamax.

Berdasarkan hasil wawancara dengan driver Gojek,Ferdy (30 tahun) menyatakan keberatan kalau harga BBM non subsidi naik,karena Dia penggunaan bahan bakar Pertamax.Pekerjaannya sebagai driver gojek sangat bergantung pada kendaraannya. Namun dari hasil wawancara dengan pengemudi Gojek yang lain, Duden (46)," kenaikan harga BBM tidak berpengaruh terhadap pendapatan saya sebagai driver Gojek ,karena saya bisa beralih ke BBM yang bersubsidi meskipun kualitasnya tidak sebagus BBM non subsidi."

Dari hasil wawancara dan observasi langsung ke objek peneliti yaitu driver Gojek,hampir $75 \%$ faktor pesaing baru dan sistem poin yang berpengaruh terhadap pendapatan mereka,sedangkan sisanya $25 \%$ harga BBM berpengaruh terhadap sebagian kecil pengemudi Gojek karena mereka memakai BBM non subsidi.

\section{Kesimpulan}

Dalam penelitian ini ditemukan bahwa faktor - faktor yang palin mempengaruhi pendapatan driver Gojek sebesar 75\% adalah pesaing baru dan sistem poin, dimana pesaing baru seperti Grab juga mulai berkembang di kota Sukabumi.Sistem poin yang berubah dari bonus tunai Rp.1.500 jika menjalankan order $6-10 \mathrm{~km}$, sekarang sudah ditiadakan lagi. Driver hanya mendapat bonus tunai Rp.3000 jika menjalankan order pada jam $23.00-05.00$.

Sedangkan sisanya $25 \%$ adalah kenaikan Bahan Bakar Minyak (BBM).Dari hasil wawancara,tidak banyak driver Gojek yang mengeluhkan berkurangnya pendapatan mereka yang disebabkan oleh kenaikan harga BBM.
Untuk PT.Gojek sebagai aplikator sebaiknya mengkaji ulang sistem poin agar para driver Gojek tidak harus lembur sampai malam untuk mengejar target poin 14 . Apalagi pesaing baru mulai bermunculan.

Penelitian ini harus dilakukan pengembangan dan penelitian lebih lanjut untuk mencari faktor - faktor lain yang dapat mempengaruhi pendapatan driver Gojek.

\section{Referensi}

Amajida, Fania Darma. 2016, Kreativitas Digital Dalam Masyarakat Risiko Perkotaan: Studi Tentang Ojek Online "Go-Jek" di Jakarta. Departmen Sosiologi Universitas Indonesia. Jurnal Informasi Kajian IImu Komunikasi Volume 46. Nomor 1. Juni 2016.

Creswell, John W. 2010, Research Design: Pendekatan Kualitatif, Kuantitatif dan Mixed. Yogyakarta: Pustaka Pelajar, https://daftargojek.blogspot.com SISTEM KOMISI GOJEK (Di akses tgl 1 Oktober 2018)

Https://id.m.wikipedia.org/wiki/Ojek

Https://www.merdeka.com Jumat, 6 Juli 2018 06:00 Reporter : Siti Nur Azzura

Https://www.transonlinewatch.com

Margono. 2004. Metodologi Penelitian Pendidikan. Jakarta: PT Rineka Cipta. Moeleong, Lexy.J. 2005. Metode penelitian. Bandung: Remaja Rosda karya.

Sugiyono. 2010. Metode Penelitian Pendidikan Pendekatan Kuantitatif, Kualitatif dan R \& D. Bandung : Alfabeta

Sugiyono. 2013. Metode Penelitian Pendidikan Pendekatan Kuantitatif, Kualitatif dan $R$ \& D. Bandung : Alfabeta 